\title{
Susana Monzon (1931-2013)
}

\section{Marie-France Fauvet-Berthelot}

\section{OpenEdition}

Journals

Édition électronique

URL : https://journals.openedition.org/jsa/12714

DOI : 10.4000/jsa. 12714

ISSN : $1957-7842$

\section{Éditeur}

Société des américanistes

\section{Édition imprimée}

Date de publication : 15 septembre 2013

Pagination : 247-249

ISSN : 0037-9174

\section{Référence électronique}

Marie-France Fauvet-Berthelot, «Susana Monzon (1931-2013) », Journal de la Société des

américanistes [En ligne], 99-1 | 2013, mis en ligne le 21 octobre 2013, consulté le 03 septembre 2022 URL : http://journals.openedition.org/jsa/12714 ; DOI : https://doi.org/10.4000/jsa.12714 


\section{NÉCROLOGIE}

Susana Monzon (1931-2013)

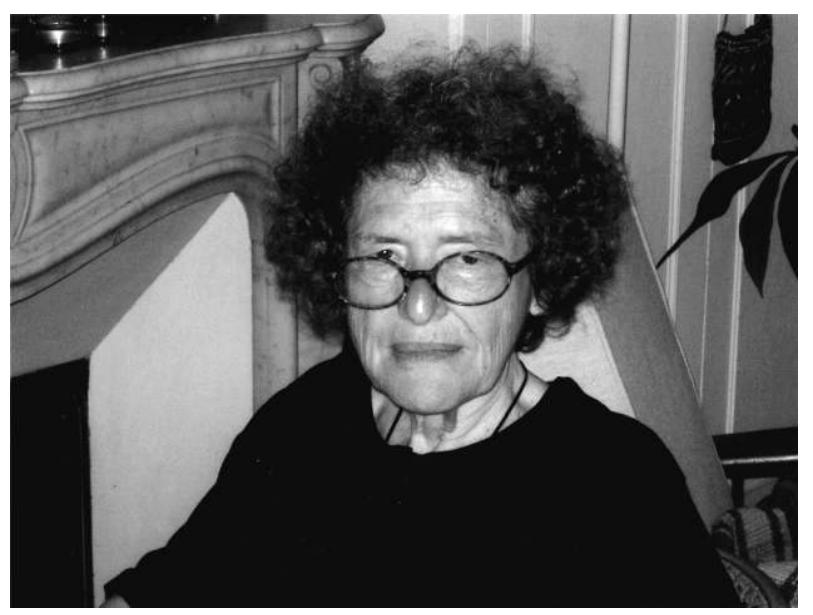

Susana Monzon.

Susana Monzon s'est éteinte le 9 mai 2013 dans un hôpital parisien. Née à Rosario, dans la province de Santa Fé en Argentine le 26 janvier 1931, elle obtint en 1956 son diplôme d'architecte à l'Université nationale du Littoral de cette ville, en même temps qu'elle suivait une formation en histoire et en archéologie. Après avoir vécu un an à Rome, elle s'installa en France en 1964 avec son mari architecte ; elle compléta alors ses études à la Sorbonne et obtint en 1967 une Licence de lettres libre (sciences humaines).

Passionnée d'archéologie depuis toujours, elle soutint en 1971 un doctorat de $3^{\mathrm{e}}$ cycle en Préhistoire dirigé par le Professeur André Leroi-Gourhan sur les styles céramiques de la Quebrada de Humahuaca, province de Jujuy (Argentine) où elle avait réalisé des fouilles. Sur le terrain comme en cabinet, l'Amérique du Sud restera son domaine de prédilection. Au musée de l'Homme, elle étudia plusieurs collections archéologiques et ethnographiques conservées au département d'Amérique. Dans les années 1990, elle donna aussi des cours en histoire de l'art précolombien à l'école du Louvre.

Membre de la mission archéologique franco-brésilienne de 1978 à 1980, elle participa avec Annette Laming-Emperaire et Niede Guidon au relevé de peintures rupestres préhistoriques dans les États de Piaui et Minas Geraes, assurant également des cours d'archéologie à l'Université fédérale de Piaui. 
Elle travailla ensuite plusieurs années avec Anne-Marie Hocquenghem au Pérou, dans la région de Piura et publia avec elle un livre sur la cuisine régionale ; elle prépara également un livre sur l'architecture traditionnelle de cette ville.

Susana Monzon s'intéressa aussi aux problèmes de terminologie et de nomenclature ; intégrée dans l'équipe du département de Technologie comparée du musée de l'Homme, elle participera à la publication d'un livre sur la terminologie céramique, et d'un autre sur la terminologie culinaire.

Ingénieur de recherche au CNRS, à mi-temps, elle assura de 1984 à 1996 le secrétariat de la Société des Américanistes, en même temps que le secrétariat de rédaction du $J S A$. Qui ne se souvient de sa disponibilité et de la gentillesse de son accueil dans le bureau de la Société au musée de l'Homme?

Enthousiaste et d'une grande rigueur intellectuelle, Susana Monzon avait un don réel pour le travail collectif - sa bibliographie en témoigne. Son humeur égale, sa vivacité d'esprit, son esprit critique en firent une remarquable collègue de travail et une amie exceptionnelle.

\section{Marie-France FAuvet-BeRTHELOT}

MNHN

\section{BIBLIOGRAPHIE DE SUSANA MONZON}

1977 «Les représentations sexuelles dans l'art rupestre brésilien », Sydney Anthonioz (collab.), Objets et Mondes, 17 (1), pp. 31-38.

1978 «Les peintures rupestres de Cerca Grande, Minas Gerais, Brésil », Sydney Picasso, Pierre Colombel et Annette Laming- Emperaire (collab.), Cahiers d'archéologie d'Amérique du Sud.

1978 Pinturas e Gravuras Pre-historicas de Sao Raimundo Nonato, Estado do Piaui. Missao Arqueologica Franco-Brasileira, Laure Emperaire (collab.), Museu Paulista, Sao Paulo.

1979 «La sépulture en urnes du nord-ouest argentin », Objets et Mondes, 19, pp. 97-103.

1980 «Préhistoire du Sud-Est du Piaui », Objets et Mondes, 20 (4), pp. 153-160.

1980-1981 «Des rapports entre les signes et les représentations anthropomorphes dans les peintures rupestres du Brésil », Journal de la Société des Américanistes, 67, pp. $125-140$.

1981-1982 «A represantacao humana na arte rupestre do Piaui : comparacoes con outras areas ", Revista do Museu Paulista, XXVIII, pp. 401-422.

1983 «Analyse des traits d'identification, étude d'un cas : la Toca da Entrada do Baixao da Vaca », Études Américanistes Interdisciplinaires, 2, pp. 36-57.

1983 «Die Felsbilder im Nationalpark "Sete Cidades", Piaui, Brasileien », Camak, pp. 5-7.

1989 L'art rupestre sud-américain. Préhistoire d'un continent, Éditions du Rocher, Paris. 
1989 Lexique et typologie des poteries. Pour la normalisation de la description des poteries, Hélène Balfet et Marie-France Fauvet-Berthelot (collab.), Éditions du CNRS, Paris.

1991 «El estudio de la cerámica y su contribución a una investigación interregional: el caso de Piura », Bulletin de l'Institut français d'Études andines, 20 (2), pp. 589-597.

1992 "Las colecciones americanas en los museos franceses », Revue des Musées royaux d'Art et d'Histoire, 63, pp. 243-250.

1992 Cuisines du monde. Gestes et recettes, Françoise Cousin (collab.), CNRS Éditions, Paris.

1993 Normas para la descripción de las vasijas cerámicas, Hélène Balfet et MarieFrance Fauvet-Berthelot (collab.), CEMCA, Mexic.

1995 La cocina piurana: ensayo de antropología de la alimentación, Anne-Marie Hocquenghem (collab.), Institut français d'Études andines, Lima.

1996 «Flores, follajes y líneas. Investigaciones sobre el estilo de la cerámica de Amatenango », Marie-France Fauvet-Berthelot (collab.), Universidad de Ciencias y Artes del Estado de Chiapas, Centro de Estudios superiores de México y Centroamérica, Anuario 1996, pp. 432-481.

2010 «Rencontres américaines », Marie-France Fauvet-Berthelot (collab.) in Matières, manières et sociétés. Hommage à Hélène Balfet, Françoise Cousin et Christian Pelras (sous la direction de), Publications de l'Université de Provence, pp. 65-70.

\section{Claude-François BAUDEZ (1932-2013)}

Au moment de mettre sous presse, nous apprenons avec tristesse le décès, survenu le 13 juillet 2013, de M. Claude-François Baudez, qui fut président de la Société des Américanistes de 1993 à 2001. Une notice lui sera consacrée dans le prochain numéro du Journal. 
